\title{
Perceptions of Medical Practitioner Regarding Adverse Drug Reactions Reporting and Pharmacovigilance
}

\author{
Nahar $\mathrm{N}^{1}$, Kan $\mathrm{TH}^{2}$, Banu $\mathrm{LA}^{3}$, Khan $\mathrm{MI}^{4}$, Hossain $\mathrm{AM}^{5}$
}

\begin{abstract}
Background: Adverse Drug Reactions (ADRs) are global problem of major concern. Spontaneous reporting of ADRs is the cornerstone of pharmacovigilance. However, underreporting is a huge problem due to lack of reporting culture among healthcare professionals. Objectives: the purpose of the present study was to assess the knowledge, attitude and practice of physicians regarding reporting of ADRs, and pharmacovigilance as well as to identify the reasons for under-reporting with suggestion for improvement in the reporting system. Methodology: This cross sectional, observational study was conducted to assess the knowledge, attitudes and practices regarding adverse drug reaction reporting among physicians working in different level hospitals of Bangladesh. Data were collected from 308 physicians during the period of January to December 2012 using structured questionnaire. Result: Response rate was 97\%. Majority of the respondent (95\%) felt that ADR reporting is necessary and it is a professional obligation. Inadequate knowledge of reporting mechanism, unavailability of reporting form, complex reporting system, lack of time and inadequate expertise were the main reasons cited for underreporting. Majority of the respondents suggested regular training sessions, strengthening the drug administration department, government law, regular follow up and inclusion of ADR reporting exercise in undergraduate and post graduate curriculum may help to improve the situation. Conclusion: The deficiency of knowledge, attitude and practice of physician regarding ADR reporting need urgent attention on priority basis not only for the success of pharmacovigilance program but also for better clinical management of the patient in general. [J Shaheed Suhrawardy Med Coll, 2014;6(1):18-22]
\end{abstract}

Keywords: ADRs, ADRs reporting, pharmacovigilance, physicians

Received: March 2014; Revised: April 2014; Accepted: May 2014

\section{Introduction}

Safety and efficacy are the two major concerns about a drug when given to a patient. An adverse drug reaction (ADRs) is the common clinical problem while treating a patient. It is defined as - any response to a medicine which is noxious and unintended and which occurs at a dose used in humans for prophylaxis, diagnosis, therapy or modification of physiological functions ${ }^{1}$. ADRs are associated with a significant morbidity and mortality ${ }^{1-2}$. Recent estimates suggest ADRs to be the fourth major cause of death in the United States of America (USA) ${ }^{1}$. This gave birth to the branch of pharmaco-vigilance. By definition, pharmacovigilance is, "The science and activities relating to the detection, assessment, understanding and prevention of adverse effects or any other drug-related problems"3. Preventing ADRs is an integral part of routine clinical work of any physician. Their active involvement in spontaneous reporting of ADRs is essential for the effective implementation of National Pharmacovigilance Program 4 .

Spontaneous reporting has contributed significantly to successful pharmacovigilance. The contribution of health

1. Prof. Dr. Nurun Nahar, Professor, Pharmacology, MH Samorita Medical College, Dhaka

2. Dr. Md. Tafazzal Hossain Khan, Associate Professor, Department of Neonatology, Dhaka Medical College, Dhaka

3. Prof. Dr. Layla Afroza Banu, Professor, Department of Pharmacology, Shaheed Suhrawardy Medical College, Dhaka

4. Dr. Md. Ismail Khan, Professor and Dean, Faculty of Medicine, Dhaka University, Dhaka

5. Dr. Ahmed Manadir Hossain, Assistant Professor, Department of Medicine, Faridpur Medical College, Faridpur

\section{Correspondence}

Prof. Dr. Nurun Nahar, Professor, Department of Pharmacology, MH Samorita Medical College, Dhaka, Bangladesh; Email: nurunnahar004@gmail.com; Cell no.: 
professionals, in this regard, to ADRs databases is enormously significant and has encouraged ongoing ascertainment of the benefit-risk ratio of some drugs ${ }^{5-6}$ as well as contributed to signal detection of unsuspected and unusual ADRs previously undetected during the initial evaluation of a $\operatorname{drug}^{7-8}$. The Uppsala Monitoring centre (UMC, WHO), Sweden is maintaining the international database of adverse drug reaction reports currently about 8 million case reports received from several national centers (111 member countries). However, still, it is estimated that only $6-10 \%$ of all ADRs are reported ${ }^{9}$. Many factors are associated with under-reporting of ADRs among health professionals. These factors have been broadly classified as personal and professional characteristics of health careers, and their knowledge and attitudes to reporting ${ }^{10}$. In order to improve the reporting rate, it is important to improve the knowledge, attitude and practices of the healthcare professionals regarding ADRs reporting and Pharmacovigilance. The best time to do it is probably during the under graduate and post graduate education of the doctors. If we can improve the awareness of ADRs reporting among physician the pharmacovigilance will be effective which may lead to prevent common drug related problems during clinical practice.

In Bangladesh under the guidance of WHO, a cell has been established in the Directorate General of Drug Administration (DGDA) in 1996. The cell is trying to introduce a systematic mechanism for ADRs monitoring program in Bangladesh for collection, analysis and compilation of ADRs which will be spontaneously reported by the medical and pharmaceutical professional from all health services outlets of the country ${ }^{11}$. But spontaneous reporting is very little and it may be due to the absence of a vibrant ADR monitoring system and also lack of a reporting culture among physicians and health care providers $^{11}$. In order to improve spontaneous reporting it is necessary to evaluate awareness and attitude of health care professionals regarding ADRs reporting and pharmacovigilance. Therefore the purpose of the present study was to assess the knowledge, attitude and practice of physicians regarding reporting of ADRs, and pharmacovigilance as well as to identify the reasons for under-reporting with suggestion for improvement in the reporting system.

\section{Methodology}

It was a cross sectional observational study was conducted on 308 physicians who were working in different medical college hospitals and Thana health complexes. Study period was January to December 2012. Physicians of different level (professor, associate professor, assistant professor, registrar, junior consultant, resident physician, medical officer, lecturer) were included for data collection. The study instrument was a pre designed questionnaire which was structured to obtain information about their knowledge, practice and attitude regarding ADRs reporting and also highlighted the factors for less reporting. Physicians were also made suggestions for possible ways to improve ADR reporting during clinical practice. Questionnaire was administered when the physicians were attending the different workshop /seminar occurred in teaching hospital on current medical affairs. The questionnaire was handed to them after explaining the purpose of the study. The physicians were requested to complete the questionnaire and returned it immediately to maximize the response. Data was calculated and stored in computer and results were expressed as percentage of opinion and displayed in table.

\section{Results}

The study was conducted on 320 physicians working in different medical college hospital and thana health complexes. 308 doctors completely fill up the questionnaire and the response rate was 97\%. Demographic data of respondent reveals that most of them from government institute $(83 \%)$, male $(69 \%)$ are more than female, medicine (46\%) specialist are more than others and maximum respondents are medical officer (62\%) (Table 1).

Knowledge: majority of physicians (93\%) perceived that among health care professional doctors are the most responsible persons who will report ADRs. Among the agents which report should be done are allopathic drugs (89\%) and vaccines $(70 \%)$ were given most important to report. Events like reaction to a new drug $(86 \%)$, serious event $(78 \%)$ and death of patients $(83 \%)$ given importance to report by the physicians (Table 2).

Practice and awareness: In this study $31 \%$ physician aware about ADRs reporting in Bangladesh, whereas only $9 \%$ physician reported to any reporting or monitoring cell. On the other hand 18\% physicians aware about local reporting system in hospital and only $10 \%$ physician reported to any local reporting system (Table 3 ).

Table 1: Demographic profile of the respondent $(n=308)$

\begin{tabular}{llcc}
\hline Variables & & Frequency & Percentage \\
\hline Type of institute & Government & 256 & 83.0 \\
& Non-government & 52 & 17.0 \\
& Total & $\mathbf{3 0 8}$ & $\mathbf{1 0 0 . 0}$ \\
\hline Sex & Male & 213 & 69.0 \\
& Female & 95 & 31.0 \\
& Total & $\mathbf{3 0 8}$ & $\mathbf{1 0 0 . 0}$ \\
\hline Department & Medicine & 143 & 46.0 \\
& Surgery & 82 & 27.0 \\
& Obstetrics and Gynecology & 48 & 16.0 \\
& Para-clinical & 23 & 7.0 \\
& Preclinical & 12 & 4.0 \\
& Total & $\mathbf{3 0 8}$ & $\mathbf{1 0 0 . 0}$ \\
\hline \multirow{2}{*}{ Designation } & Professor, Associate Professor, & 42 & 14.0 \\
& Assistant Professor & & \\
& Consultant, Resident Physician & 74 & 24.0 \\
& Registrar, Assistant registrar & & \\
& Medical officer & 192 & 62.0 \\
& Total & $\mathbf{3 0 8}$ & $\mathbf{1 0 0 . 0}$ \\
\hline
\end{tabular}

*Medicine= Internal medicine, pediatrics, skin, psychiatry, pulmonology, cardiology; Surgery $=$ general surgery, Eye, ENT, orthopedics, pediatric surgery, maxofacial surgery; Paraclinical=Pathology, Microbiology, Pharmacology, Forensic medicine, Community medicine; Preclinical= Anatomy. Physiology, Biochemistry; Medical officer=MO. IMO, EMO 
Table II: knowledge about adverse drug reaction reporting among the physicians $(n=308)$

\begin{tabular}{lcc}
\hline $\begin{array}{l}\text { 1. Professionals to whom ADRs } \\
\text { should be reported }\end{array}$ & Frequency & Percentage \\
\hline \multicolumn{1}{c}{ Doctor } & 288 & \\
Dentist & 90 & 93 \\
Nurse & 95 & 30 \\
Pharmacist & 91 & 29 \\
Physiotherapist & 26 & 8 \\
\hline 2. Agents related to this be reported & Frequency & Percentage \\
Allopathic drugs & 273 & 89 \\
Homeopathic drugs & 129 & 42 \\
Herbal product & 152 & 49 \\
Blood product & 170 & 55 \\
Biological agent & 152 & 49 \\
Vaccines & 216 & 70 \\
Medical devices & 111 & 36 \\
\hline 3. Events which can be reported & Frequency & Percentage \\
a) Reaction to a new drug & 276 & 86 \\
b) Serious event & 241 & 78 \\
c) Unusual event & 168 & 61 \\
d) ADR Like reaction & 155 & 56 \\
e) Any suspected drug reaction & 168 & 54 \\
f) Well recognized ADR & 152 & 49 \\
g) Congenital anomalies & 151 & 49 \\
h) Death of patient due to ADRs & 258 & 83 \\
\hline
\end{tabular}

*ADR Like reaction: Any reaction that appears like an ADR but the cause is not certain

Table 3: Physicians awareness and practices regarding ADRs reporting system $(n=308)$

\begin{tabular}{ll}
\hline Question & Response \\
\hline $\begin{array}{l}\text { Awareness regarding ADR reporting and } \\
\text { monitoring in Bangladesh }\end{array}$ & Aware 31\% \\
$\begin{array}{l}\text { Have you reported any suspected ADR to } \\
\text { any reporting / monitoring center }\end{array}$ & $\begin{array}{l}9 \% \text { have } \\
\text { reported }\end{array}$ \\
$\begin{array}{l}\text { Awareness of existence of ADRs reporting } \\
\text { and monitoring at your hospital }\end{array}$ & $18 \%$ aware \\
$\begin{array}{l}\text { Did you report any suspected drug reaction } \\
\text { to any ADR reporting and motoring system } \\
\text { existing at your hospital }\end{array}$ & $10 \%$ reported \\
\hline
\end{tabular}

Attitude: Regarding attitude towards ADRs reporting 98\% physicians suggested that it is necessary and $90 \%$ physician felt it is a professional obligation and $76 \%$ physicians seems it should be compulsory. Factors for less reporting: most of the physicians perceived that they do not know where, how and when to report $(82 \%)$, seems report may be wrong $(29 \%)$, reporting form not available $(76 \%)$, level of clinical knowledge make difficult to decide about ADRs (31\%) and lack of time to actively look for reaction (25\%) (Table 4$)$.

\section{Discussion}

ADRs reporting and monitoring is in infant stage in Bangladesh. This study will help in knowing the physicians knowledge, practice and attitude towards ADRs reporting, cause for less reporting with suggestion to improve reporting. Overall response rate was $97 \%$ which is higher than other study ${ }^{4,12}$. The study pointed out that the awareness about ADRs reporting system among physicians were low. Only few physicians (9\%) reported ADRs to any monitoring organization which is similar to other findings ${ }^{12,13}$. This result suggested that the ADRs reporting and monitoring is not adequate and need serious rethinking for improvement the situation.

Though it is known to the physicians that the medical professionals like doctors can report an ADR, the awareness that even a dentist $(29 \%)$, a nurse $(30 \%)$, pharmacist (29\%) and physiotherapist (08\%) can do so is very low. Active involvement of the paramedical stuff in spontaneous reporting of ADR will go a long way in improving the reporting rates, since they are in closer contact with the patients for a longer duration than the doctors $^{12}$. Also it is a general perception that ADR reporting is only for allopathic drugs and vaccines. The knowledge that it encompasses other products like herbals, traditional medicines and blood product, biological product and medical devices is comparatively low. Same observation was made by Gupta et $\mathrm{al}^{12}$.

It was found that majority of the doctors $(98.0 \%)$ felt that ADRs reporting is necessary and it is a professional obligation $(90.0 \%)$. Physicians perceived that events to new drugs $(86 \%)$, only serious event and reaction that cause death are most important aspect of pharmacovigilance. The awareness that even suspected drug reaction, congenital anomalies and unusual event should require equal importance when reporting ADRs. In one study Li-Qing et $\mathrm{al}^{13}$ observe that most $(66.0 \%)$ doctors are aware and willing to report suspected ADRs and in another study Bateman et $\mathrm{al}^{14}$ found that majority of doctors would like to report those which are already well known.

In this study majority (76.0\%) of the physicians opined that ADRs reporting should be compulsory and very few perceived that it should be voluntary $(23.0 \%)$ and remunerated $(2.0 \%)$, this findings not related to others ${ }^{12,14}$ where physicians perceived ADRs reporting should be voluntary $(88.0 \%)$ and remunerated $(73.0 \%)$. On the other hand most $(54 \%)$ of the physicians felt that existing reporting system is not useful to practice and they $(52 \%)$ did not feel encourage to report further through this system which is not consistent with other findings ${ }^{12-13}$.

The factors discouraging physicians to report were lack of knowledge where, how and when to report $(82.0 \%)$ and unavailability of ADR reporting form (76.0\%). This finding partially relate to Gupta et $\mathrm{al}^{12}$ findings where doctors mention that lack of understanding of reporting system and lack of clinical knowledge and lack of time to actively look for reaction to report. Other less important factors that physicians pointed out for less reporting were concerned that report may be wrong $(29.0 \%)$, lack of time to fill up the form $(21.0 \%)$, reporting may generate extra work $(22.0 \%)$ and lack of clinical knowledge (31.0\%). 
Table IV: Physicians attitude towards reporting of adverse drug reactions (n=308)

\begin{tabular}{|c|c|c|}
\hline 1. ADRs reporting is necessary & Frequency & Percentage \\
\hline Yes & 302 & 98.0 \\
\hline No & 06 & 2.0 \\
\hline Total & 308 & 100.0 \\
\hline 2.ADRs reporting is a professional obligation & Frequency & Percentage \\
\hline Yes & 276 & 90 \\
\hline No & 32 & 10 \\
\hline Total & 308 & 100.0 \\
\hline \multicolumn{3}{|l|}{ 3.ADR reporting should be } \\
\hline Voluntary & 68 & 23 \\
\hline Compulsory & 234 & 76 \\
\hline Remunerated & 06 & \\
\hline Total & 308 & 100.0 \\
\hline 4.Discouraging factors for ADRs reporting & Frequency & Percentage \\
\hline Concern about report wrong & 89 & 29 \\
\hline Do not know how to report, where to report, and when to report & 254 & 82 \\
\hline Reporting forms not available & 233 & 76 \\
\hline Lack of time to fill up the form & 65 & 21 \\
\hline Concern that report may generate extra work & 69 & 22 \\
\hline Lack of time to actively look for ADRs while at work & 77 & 25 \\
\hline Level of clinical knowledge & 97 & 31 \\
\hline Lack of confidence to discuss the ADR & 58 & 19 \\
\hline Total & 308 & 100.0 \\
\hline 5. Activities to improve spontaneous ADRs reporting & Frequency & Percentage \\
\hline Strengthen training program on ADR reporting o & 276 & 89 \\
\hline ADRs reporting should be compulsory in-service training & 253 & 82 \\
\hline Institutional role should be more active o & 264 & 85 \\
\hline Report forms should be included in prescribing pad & 196 & 63 \\
\hline An uncomplicated reporting system with quick feedback & 180 & 58 \\
\hline Reporting exercise should be included in undergraduate examination & 198 & 64 \\
\hline Total & 308 & 100.0 \\
\hline
\end{tabular}

To improve spontaneous reporting $89 \%$ physicians suggested to strengthen training, $82.0 \%$ says ADRs reporting should be compulsory in service training, institutional role should be more active $(85.0 \%)$, reporting form should be included in prescribing pad $(63.0 \%)$, reporting system should be uncomplicated with quick feedback $(58.0 \%)$, reporting exercise should be included in undergraduate curriculum $(64.0 \%)$. A study conducted by Gupta and Udupa ${ }^{12}$ where physicians suggested training on ADRs reporting and easy system of reporting will improve the situation. In another study Tabali et $\mathrm{al}^{15}$ demonstrated that educational intervention can increase physician awareness of ADRs and regular retraining also essential.

In this study physicians additional suggestion on how to improve the ADRs reporting system were strengthen drug administration, making form available at all level of hospital, regular follow up of reporting at least every 6 month or yearly, Government strong policy and law, booklet produced by health ministry and supplied it to all level of hospital and health care facility, public education, patient awareness, practice rational use of medicine, avoid poly-pharmacy, limit antibiotic use etc. The situation will change very soon but if reporting of ADRs will regulary practice it will ensure more safer use of medicin. Government, health care professionals and patients all jointly may play active role in this situation to ensure better health care and minimize drug related harm to patients while prescribing. Awareness program through training, regular workshop, publicity, inclusion in undergraduate and post graduate curriculum and in service training may improve the situation. Health care professionals should play active role regarding pharmacovigilance and to address the various perceived obstacles to spontaneous reporting which will hopefully fill observed lacunae in knowledge and practices. A close relationship between physician, the pharmacovigilance centre and the Government are also suggested. Attitudinal and cultural changes like pharmacovigilance is seen as an integral part of the clinical activities of the physicians are very necessary for a long term improvement of ADRs reporting.

The limitation of the study is that it would be more 
scientific if quantitative methodology (in depth interview, focus group discussion) for such a study may be useful to gain better understanding of knowledge and attitude of physicians regarding reporting of ADRs. In order to generalize our findings it is imperative that similar studies may be done on a national basis in all teaching hospitals of the country. Study finding cannot be applied to the wider medical community as it only restricted to some health complex and few medical college hospital of Bangladesh.

\section{Conclusion}

The present study strongly suggests that awareness regarding ADRs reporting and monitoring is very poor among physicians which automatically affect reporting. Therefore there is a great need to create awareness regarding the reporting of ADRs among medical practitioners which will make the pharmacovigilance strong in future.

\section{Acknowledgement}

The authors wish to thanks all the physicians who participated in the study.

\section{References}

1. Lazarou J, Pomeranz BH, Corey PN. Incidence of adverse drug reactions in hospitalized patients-a meta-analysis of prospective studies. JAMA 1998; 279: $1200-5$

2. Classen DC, Pestotnik SL, Evans RS et al. Adverse drug events in hospitalized patients. JAMA 1997;277(4):301-6

3. World Health Organization. Safety of medicines: A guide to detecting and reporting adverse drug reactions. Geneva: 2002. WHO/EDM/QSM/2002.2

4. Amrita P, Singh SP. Status of spontaneous reporting of adverse drug reaction by physician in Delhi. Indian J Pharmacy Practice. 2011;4(2), 29-36 5. Edwards I, Olsson S.WHO; global monitoring. In Pharmacovigilance Edited by Mann RD, Andrew E, Chichester John Wiley \& Sons; 2002. 169182. Available from: http://onlinelibrary.wiley.com/doi/ 10.10020470853093.ch13/summary

6. Ahmad SR. Adverse drug event monitoring at the Food and Drug Administration. J Gen Intern Med 2003, 285: 437-443

7. Wysowsky DK, Swartz L. Adverse drug event surveillance and drug withdrawals in the United Statesn. 1969-2012. The importance of reporting suspected reactions. Arch Intern Med 2005, 165: 1363-1369

8. Lexchin J. Is there a role for spontaneous reporting of adverse drug reactions? CMAJ 2006, 174, 191-192

9. Feely J, Moriarty S, O'Conner P. Stimulating reporting of adverse drug reaction by using a fee. Br Med J, 300: 22-23

10. Inman WH. Attitude to Adverse drug reaction reporting. Br. J Clin Pharmacol. 1996; 41, 433-435

11. Adverse drug reactions and adverse drug reactions monitoring (ADRM) Appendix-11; BDNF. 3rd edn. 2010. Pg 600-608

12. Gupta P. Udupa A. Adverse Srug Raction Reporting and Pharmacovigilance: Knowledge, Attitude and perceptions amongst Resident Doctors. J Pharm Sci Res 2011; 3(2):1064- 69

13. Qing L, Su-min, Z, Hua ting C, Shi-ping. F, Xin. Ydong. L, Lu-yuun. S, Fan-Dian. Z. Awareness and attitude of healthcare professionals in Wuhun, China to the reporting of adverse drug reactions. Chinese Medical Journal; 2004; 117(6). 856- 861

14. Bateman DN, Sundars GLS, Rawlins MD. Attitude to adverse drug reaction reporting in the Northern Region. Br J Clin Pharmacol 1992;34(5): 421-26

15. Tabali M, Leschke E, Bockelbrink A, Witt CM, Willich SN, Ostermann $\mathrm{T}$, Mathes $\mathrm{H}$. Educational intervention to improve physician reporting of adverse drug reactions (ADRs) in a primary care setting in complementary and alternative medicine. BMC Public Health. 2009. 9/274 